\title{
Financing Innovation and Circular Economy
}

\author{
L. Goovaerts, C. Schempp, L. Busato, A. Smits, L. Žutelija \\ and R. Piechocki
}

\begin{abstract}
In the seminar on "Financing Innovation and the Circular Economy (CE)", organized by the European Investment Bank (EIB) in the context of the Life Cycle Management Conference 2017, experts of the EIB and EIB partner institutions (European Commission, Rabobank) spoke about the specific challenges involved in the transition to a $\mathrm{CE}$ and the role played by their institutions in accelerating this transition by means of appropriate funding, financing and advisory instruments. In short presentations, the speakers first explained the broader role of the EIB and the European Commission (EC) in supporting the transition to CE, as well as the general types of $\mathrm{CE}$ projects and the specific questions that project promoters can expect in project appraisal. EC, EIB and Rabobank representatives also presented the concrete support and products offered to innovative circular economy project promoters.
\end{abstract}

\section{Introduction}

In view of the world's limited resources and the predicted demographic developments, the currently prevailing linear economic model appears to be unsustainable from both economic and environmental points of view. The answer lies in transition to the CE business model, which requires nothing less than an economic paradigm shift and a radical change in the mind-set of policy-makers, businesses, consumers and financiers towards more life-cycle thinking. CE, as defined by the EIB and the EC, "attempts to encompass all economic systems where the resources used for a product or a service are maximally reduced and/or recycled, while either main-

L. Goovaerts · C. Schempp $(\bowtie) \cdot$ L. Busato · A. Smits

European Investment Bank, Luxembourg City, Luxembourg

e-mail: c.schempp@eib.org

L. Žutelija

European Commission, Brussels, Belgium

R. Piechocki

Rabobank, Utrecht, The Netherlands

(C) The Author(s) 2018

E. Benetto et al. (eds.), Designing Sustainable Technologies,

Products and Policies, https://doi.org/10.1007/978-3-319-66981-6_47 
taining to the best extent possible their economic value at all times and/or ensuring that they are biologically degraded. CE-related projects focus on re-thinking and redesigning products, processes, value chains, business and service models in order to achieve the above-specified purpose" [1].

The circular economy can be seen as a green giant on the rise, on account of its enormous potential to unleash sustainable growth and job creation as well as the increasing traction it is gaining in the business world. Many businesses in different sectors have already started to tap into this potential, displaying a large variety of innovative technologies and business models. However, the transition to a $\mathrm{CE}$ is no certain success and needs to tackle a number of hurdles. Ensuring access to finance for innovative circular businesses, throughout their different growth phases, is one of them.

\section{Challenges and Opportunities in Financing CE Projects}

Besides its environmental benefits, the circular economy offers tremendous economic potential, which businesses in different sectors have started tapping into, displaying a large variety of innovative technologies and business models. However, CE projects present a number of different challenges to access return-based finance. On the one hand, the new technologies and business models proposed are often unproven and complex, rely on uncertain supply chains and operate in uncertain markets. Furthermore, CE projects usually involve small sub-investment grade promoters, with limited collateral or few physical assets. Because of the increased market and credit risks involved, the CE promoters often have limited access-to-finance or face increased cost of capital. A study published in 2015 by the Innovation Finance Advisory unit of the EIB on access-to-finance conditions of projects supporting CE concluded that while market forces (commodity price fluctuations) alone could create a circular economy there is a risk of a slow transition and high opportunity costs [1]. Hence, there is space (and need) for policy intervention and support in form of innovative funding and financing instruments.

\section{Financing of Innovation and Circular Economy in Practice}

\subsection{The EIB in the Circular Economy}

Mr. Schempp explained the crucial role of the EIB, as the EU Bank, in bridging financing gaps and catalysing strategic investments in key EU policy areas such as $\mathrm{CE}$, not only through tailored financial instruments but also through specialized 
advisory services. With the EC's support, the EIB has reinforced the technical and financial advisory services available to projects through the European Investment Advisory Hub (EIAH) and the Innovation Finance Advisory unit. As further explained by Ms. Busato, given the unique combination of risk features, the EIB provides advice to $\mathrm{CE}$ project promoters on structuring and financing to improve the bankability of their projects.

CE projects are generally eligible for EIB financing as these are well aligned with one or more of the bank's central policy objectives including the support of environmental protection and resource efficiency, research and innovation and SME financing. In the last 5 years, the EIB lent around 2.4 billion to $\mathrm{CE}$ projects in diverse sectors including typical infrastructure sectors such as water and waste management, as well as in the agribusiness and bio-economy and industry and services sectors.

\subsection{The European Commission's Perspective: From Funding to Financing}

The representative of the European Commission provided an overview of EU's general policy and available funding sources from the Horizon 2020 and LIFE programmes as well as from the European Structural and Investment Funds (ESIF). These programmes are designed to attract funding from other public or private investors in key EU priority areas including CE. Non-reimbursable EU funding in the form of grants will continue to play a role in reducing the overall cost and risk, and help boost the credit rating of innovative projects that otherwise would not have seen the light of day. Simultaneously, the EC is increasingly promoting the integration of available EU funds with financial instruments and products such as loans, guarantees, equity and other risk-bearing mechanisms, as a means of enhancing the scope and leveraging the impact of the EU budget.

In this regard the EC representative mentioned the combined efforts of the EC and the EIB Group in setting up such financial instruments and risk-bearing mechanisms.

\subsection{Joint Initiatives of the EIB and the European Commission in Support of CE}

With the backing of EU guarantees granted to the European Fund for Strategic Investment (EFSI) and the "EU Finance for Innovators" (InnovFin) Programme, the EIB is being enabled to take on more risk and help more CE projects with medium to high risk profiles get off the ground. 
EFSI is one of the three pillars of the Investment Plan for Europe introduced in 2015 and aims to help to finance strategic investments in key areas with relevance for the $\mathrm{CE}$ such as infrastructure, research and innovation, renewable energy and energy efficiency as well as risk finance for small and medium-sized enterprises (SMEs) [2].

InnovFin is available since 2014 and consists of a range of tailored productsfrom guarantees for intermediaries that lend to SMEs to direct loans to enterprises -helping support the smallest to the largest R\&I projects in the EU and countries associated to Horizon 2020 [3]. Following the recommendation of the EIB study on access-to-finance conditions for projects in CE, the EC and EIB amended the InnovFin Programme to include business model innovation (not only technology innovation) as an eligibility criterion [4]. Further, InnovFin also has dedicated financing instruments in key areas relevant to CE. This is the case of the Energy Demonstration Projects facility and the Circular Bio-economy investment platform.

A third example of a successful EIB-EC collaboration with relevance for the $\mathrm{CE}$ is the programme for the Competitiveness of Enterprises and Small and Medium-sized Enterprises (COSME), managed by the European Investment Fund (EIF). The programme aims to improve access to finance for SMEs through two financial instruments that have been available since August 2014: Loan Guarantee Facility and Equity Facility for Growth [5].

Finally, the European Commission has partnered with the EIB to launch the Circular Economy Finance Support Platform. The platform aims to "enhance the link between existing instruments, such as the European Fund for Strategic Investments and the InnovFin-EU Finance for Innovators initiative backed by Horizon 2020, and potentially develop new financial instruments for circular economy projects." The platform is based on three pillars: the first pillar will ensure coordination and awareness raising by providing support to the Circular Economy Financing Expert Group. The second pillar will focus on advisory services. The third pillar will assess the possibility and the need for new dedicated financial instruments for circular economy projects [6].

\subsection{Practical Issues for Financing CE Projects}

As explained by Mrs. Goovaerts and Mr. Piechocki, CE specialists of EIB and Rabobank, their institutions only finance sound and sustainable CE projects. A sound circular project optimises the use and life of assets and products, closes material loops to maintain or recover their economic value at end-of-life, and uses sustainably sourced secondary raw materials, renewable or regenerative resources. Secondly, a sound circular project is expected to be a part of the long term strategy of the company and integrated in the business operation and its environment, including a well-established cooperation with reliable partners within the value chain. Moreover, a sound circular business model shows clearly identifiable demand for circular products, materials or services resulting in reliable and 
sufficient cash-flows to support the repayment of the loan. At last, a sound circular project is run by a competent, experienced promoter able to successfully implement a challenging CE project.

As explained by Mr. Smits, EIB loan officer, the EIB can either lend directly to individual borrowers/projects or, in the case of smaller borrowers/projects, through financial intermediaries. Direct financing is typically made available in the form of senior or subordinated loans for larger projects. The EIB can provide direct financing where the project investment cost is of a minimum of EUR $15 \mathrm{~m}$. In such cases, the EIB carries its own due diligence of the borrower and the project. In all cases the EIB finances a maximum 50\% of the project investment cost.

In the case of smaller projects or promoters (SMEs and MidCaps), the EIB provides intermediated financing via local banks, investment platforms and funds in the form of loans or guarantees. For instance, the EIB has provided several credit lines to its Dutch partner bank Rabobank, which the bank on-lends to 'eligible' SMEs and Mid-Caps at a reduced interest rate. A recent example is the Rabobank Impact Loan for SMEs and MidCaps III with a total credit line of EUR $200 \mathrm{~m}$. The impact loan includes circular businesses as 'eligible' borrowers. In case of intermediated financing, the EIB establishes the eligibility criteria for projects and promoters to be financed, while the due diligence of the final borrower/project is the responsibility of the intermediary financing institution.

\section{Q\&A and Future Perspectives}

The workshop concluded with a Q\&A session. The opening question enquired to what extent the banking sector considers companies' environmental risk profile. As explained by Ms. Goovaerts, EIB specialist on innovative industries, environmental and social impact is always taken into consideration, and compliance with relevant EU legislation is verified. An adjustment of risk assessment methodologies to reflect the unique character of CE projects is something the EIB is currently looking into. In a similar vein, Mr. Piechocki, sustainable business specialist at Rabobank, confirmed that supply chain policies and sustainability risk are always assessed. The bank also assists the clients in finding solutions, in case a risk has been identified.

The next question was directed towards the European Commission representative. Ms. Žutelija, CE policy officer, was asked about the future perspective to develop a set of environmental indicators harmonised at EU level to provide environmental profile of a company including its supply chain. Ms. Žutelija reconfirmed that a harmonised approach at EU level is needed and pointed out that the EC continues working to set up a harmonised system. In this context, the EC is currently finalising the pilot phase of the Product and Organisation Environmental Footprint life-cycle based methodology (PEF and OEF), and is considering future policy options related to measuring the environmental performance of products and organisations throughout their lifecycle. 
Another participant enquired which gaps in CE financing should be addressed in the future. Mr. Schempp, EIB specialist on CE, replied that in the past the EIB has built up a long track record in financing traditional recycling and resource efficiency projects. In the last few years, the bank has increased its risk taking capacity through the establishment of the EFSI and InnovFin programmes and is thus in a better position to provide financing to more innovative circular economy projects and business models. While the financing risk may be increased, such projects are expected to deliver higher economic and environmental benefits. Ms. Busato, EIB Innovation Finance Advisor, pointed out that as long as providers of return based finance and credit rating assessment institutions fail to account for the additional risk associated with the linear economy projects, there will be a gap in methodologies for assessment. The next step is establishing standard methodologies calculating economic return based on a balanced approach to linear and circular risks.

\section{References}

1. European Investment Bank Advisory Services, Access-to-finance conditions for Projects supporting Circular Economy, Report, Luxembourg 2015

2. <http://ec.europa.eu/growth/industry/innovation/funding/efsi_en> (Accessed 12.10.2017)

3. <https://ec.europa.eu/programmes/horizon2020/en/news/innovfin-\%E2\%80\%93-eu-financeinnovators-new-financial-instruments-help-innovative-firms-access-finance> (Accessed 12.10. 2017)

4. <http://www.eib.org/infocentre/press/releases/all/2015/2015-299-eu-opens-up-eur24bn-ofexisting-finance-to-circular-economy-businesses-in-support-of-eu-climate-goals.htm> (Accessed 12.10.2017)

5. <http://ec.europa.eu/growth/access-to-finance/cosme-financial-instruments_en> (Accessed 12. 10.2017)

6. <http://europa.eu/rapid/press-release_IP-17-104_en.htm> (Accessed 12.10.2017)

Open Access This chapter is licensed under the terms of the Creative Commons Attribution 4.0 International License (http://creativecommons.org/licenses/by/4.0/), which permits use, sharing, adaptation, distribution and reproduction in any medium or format, as long as you give appropriate credit to the original author(s) and the source, provide a link to the Creative Commons license and indicate if changes were made.

The images or other third party material in this chapter are included in the chapter's Creative Commons license, unless indicated otherwise in a credit line to the material. If material is not included in the chapter's Creative Commons license and your intended use is not permitted by statutory regulation or exceeds the permitted use, you will need to obtain permission directly from the copyright holder. 